\title{
Electrophoretic and Immunochemical Demonstration of the Existence of Four Human Pepsinogens *
}

\author{
Irving Kushner, $\dagger$ Wolfgang Rapp, and Pierre Burtin \\ (From the Service d'Immunochimie, Institut de Recherches Scientifiques sur le Cancer, \\ Villejuif [Seine], France)
}

In previous work from this laboratory, extracts of noncancerous human gastric mucosa were studied by immunochemical and electrophoretic means (1). Gastric mucosal extracts obtained by homogenization at $\mathrm{pH} 8$ were subjected to electrophoresis in agar at $\mathrm{pH}$ 8.2. Zones of proteolytic activity at $\mathrm{pH} 2$ were developed directly on the agar by the technique of Uriel (2). Four electrophoretically distinct zones showing proteolytic activity maximal at or near $\mathrm{pH} 2.0$ were found in each of 45 stomachs studied. Thirty-six stomachs were from patients with duodenal ulcer, seven from patients with gastric ulcer, and in two cases, were normal stomachs obtained at autopsy from patients dying of heart disease less than 24 hours before autopsy. These constituents were designated proteases (P) I, II, III, and IV in order of decreasing electrophoretic mobility.

Immunoelectrophoretic studies of gastric mucosal extracts, using antiserum to mucosal extracts, showed three of the proteolytic constituents, P II, III, and IV, to be antigenic and to differ immunochemically from one another (1). These antigens were found in all noncancerous stomachs studied. Preliminary studies of the noninvolved gastric mucosa of 10 patients with gastric carcinoma suggested that the proteolytic constituents were diminished or absent (3). It was thus of considerable interest to define more fully the nature of these gastric mucosal components.

The activation of pepsinogen involves the splitting off of basic peptides, resulting in an increased electrophoretic mobility for pepsin. This reaction

* Submitted for publication August 5, 1963; accepted June 29, 1964.

Presented in part to the Midwestern Section of the American Federation for Clinical Research, October 31, 1963. (Clin. Res. 1963, 11, 292).

$\dagger$ Present address: Department of Medicine, Metropolitan General Hospital and Western Reserve University School of Medicine, Cleveland, Ohio. is almost immediate at $\mathrm{pH} 2.0$ and is much slower at $\mathrm{pH}$ values greater than 4.0 (4). Once activation has occurred, return to a $\mathrm{pH}$ greater than 6 results in alkaline denaturation of pepsin with loss of proteolytic activity (5). When tested under appropriate conditions, a strong immunologic cross-reaction between pepsin and pepsinogen can be shown (6).

The assumption was made that the proteolytically active components of gastric mucosal extracts (P I, II, III, and IV) were in fact proenzymes (pepsinogens) and that the proteolytic activity they manifested after electrophoresis resulted from activation in situ in the agar by the acidification attendant upon addition of the substrate at $\mathrm{pH} 1.9$.

The present work demonstrates that: 1) The electrophoretic mobility of P I, II, III, and IV is rapidly increased by acidification at $\mathrm{pH} 2$ and slowly or not at all changed at $\mathrm{pH}$ values of 4.4 or greater. 2) Alkalinization following acidification results in loss of proteolytic activity of three of these constituents. 3) An immunologic relationship can be shown between the acidified and unacidified forms of the three antigenic proteolytic constituents. 4) After acidification at least five electrophoretically distinct enzymes are detectable. 5) One of these human pepsinogens (P II) is shown to be immunologically related to purified porcine pepsinogen, and another ( $P$ IV), after activation, displays several of the characteristics of pork pepsin B (7).

\section{Methods}

Extracts of gastric mucosa. Extraction of human gastric mucosa was carried out as follows: Stomachs were obtained at surgery from patients with gastric or duodenal ulcers, and in two cases, at autopsy from patients without either gastric or duodenal disease. The gastric mucosa was separated from the underlying mus- 
cularis and connective tissue, cut into small fragments, and washed in $0.033 \mathrm{M}$ phosphate buffer at $\mathrm{pH} 8.0$.

The wash solution was centrifuged at $6,000 \mathrm{rpm}$ for 30 minutes, and the precipitate, designated "mucus," lyophilized. The mucosal fragments were homogenized in $0.033 \mathrm{M}$ sodium phosphate buffer at $\mathrm{pH} 8.0$ and centrifuged at $15,000 \mathrm{~g}$ for 30 minutes, and the supernatant fluid was lyophilized. This supernatant fluid, referred to as mucosal extract, was employed for these studies. The experiments described in this report were performed with mucosal extracts from patients with duodenal ulcer.

Preparation of antisera. Rabbits were immunized with either mucosal extracts or the "mucus" residue obtained from the wash solution. Immunization was carried out by the injection of these preparations in Freund's adjuvant into the foot pads. Five to eight $\mathrm{mg}$ protein in $1 \mathrm{ml}$ was administered. Two weeks later the same preparation in alum was injected subcutaneously and then intravenously on the succeeding 2 days. Five to eight $\mathrm{mg}$ protein was given with each injection. Rabbits were test bled 5 days after the last injection and exsanguinated if antibody was present. In the absence of antibody formation, repeated courses of antigen in alum or in Freund's adjuvant were given. Antisera to each preparation were pooled. Antibodies to P II and III were found in antisera prepared to mucosal extracts. One rabbit produced antibodies to P II but not to P III, and this antiserum was not pooled with the others. Antibodies to $P$ IV were present in high concentration in antisera to "mucus" and in weak concentration in some antisera to mucosal extract. Reactivity with plasma proteins was removed by absorption with lyophilized normal human plasma.

Immunochemical and electrophoretic techniques. Immunoelectrophoretic analysis (IEA) was carried out by standard techniques (8) with only slight modification. The technique of Uriel (2) was employed to demonstrate proteolytic activity after electrophoresis in agar (see below). For analysis of chromatographic fractions, both IEA and electrophoresis before development of proteolytic activity were carried out in agar buffered at $\mathrm{pH} 8.2$ with $0.05 \mathrm{M}$ Veronal buffer. The same conditions were employed for IEA of absorption studies. All other electrophoretic studies and IEA were carried out at $\mathrm{pH}$ 5.6. Difco Noble agar ${ }^{1}$ was made up to $1.5 \%$ in $0.02 \mathrm{M}$ citrate buffer, $\mathrm{pH} 5.6$, and electrophoresis was carried out with the same buffer in the electrophoresis trays. Double diffusion in agar (Ouchterlony technique) was carried out with $1.5 \%$ agar in citrate buffer at $\mathrm{pH} 5.6$, or in Veronal buffer at $\mathrm{pH} 8.2$.

Characterization of proteolytic activity. To demonstrate proteolytic activity after electrophoresis, 24- $X$ $18-\mathrm{cm}$ glass plates were covered with a $2 \mathrm{~mm}$-thickness of agar. Reservoirs were cut near the cathodic end of the plate and filled with $0.05 \mathrm{ml}$ of a mixture containing equal parts of unbuffered $3 \%$ agar and a solution of whole gastric extract containing $5 \mathrm{mg}$ of protein per $\mathrm{ml}$. When purified products were studied, appropriately

1 Difco Laboratories, Detroit, Mich. smaller quantities of protein were used. Protein concentration was estimated by the biuret procedure with human serum albumin as standard. Electrophoresis was carried out for 2 hours at a potential difference of $7 \mathrm{v}$ per $\mathrm{cm}$, the plate being refrigerated by trays of ice. After electrophoresis, the agar plate was immersed for 30 minutes in a solution of $0.2 \%$ human serum albumin ${ }^{2}$ in $0.2 \mathrm{M}$ glycine- $\mathrm{HCl}$ buffer at $\mathrm{pH} 1.9$. This solution was then decanted, and the agar plates (containing the imbibed substrate-buffer solution) were incubated in a moist chamber for 2 hours at $37^{\circ} \mathrm{C}$. The agar was fixed overnight in a solution of $5 \%$ acetic acid in $50 \%$ alcohol, dried, and stained for protein with amido black. The imbibed albumin was stained by the dye, whereas sites of proteolytic activity in the agar remained unstained.

For IEA, the agar was dissolved in citrate buffer, $\mathrm{pH}$ 5.6 , as described above, and electrophoresis was carried out for 1 to $1 \frac{1}{2}$ hours at 6 to $7 \mathrm{v}$ per $\mathrm{cm}$.

Anion exchange chromatography. Chromatography was carried out at $4^{\circ} \mathrm{C}$. The lyophilized gastric extract was dissolved in distilled water at a concentration of 20 to $40 \mathrm{mg}$ protein per $\mathrm{ml}$ and dialyzed against $0.01 \mathrm{M}$ $\mathrm{KH}_{2}-\mathrm{K}_{2} \mathrm{H} \mathrm{PO}_{4}$ buffer, $\mathrm{pH} \mathrm{7.0,} \mathrm{for} \mathrm{at} \mathrm{least} 4$ hours. Ten to $15 \mathrm{ml}$ was introduced on to a $20-\times 2-\mathrm{cm} \mathrm{DEAE}$-cellulose column equilibrated with the same buffer. This starting buffer was passed through the column until the absorption at $280 \mathrm{~m} \mu$ returned to a stable low level. A gradient was then begun employing a modification of the technique of Fahey, McCoy, and Goulian (9) with 500 $\mathrm{ml}$ of starting buffer in the round mixing chamber and $250 \mathrm{ml}$ of $0.4 \mathrm{M}$ phosphate buffer, $\mathrm{pH} 5.65$, in the conical reservoir. A flow rate of $20 \mathrm{ml}$ per hour was utilized. After both flasks were empty, $0.4 \mathrm{M} \mathrm{PO}_{4}$ buffer, $\mathrm{pH}$ 5.65 , was passed until the curve of absorption at $280 \mathrm{~m} \mu$ returned to a stable level. $\mathrm{NaCl}, 0.8 \mathrm{M}$ in $0.4 \mathrm{M}$ phosphate buffer at $\mathrm{pH} 5.4$, was then passed through the column. Fractions containing $10 \mathrm{ml}$ of eluate were collected, and the curves of absorption at 280 and $260 \mathrm{~m} \mu$ were determined to permit estimation of the relative amount of protein and nucleic acid present. Pools of two or three adjacent tubes were made, dialyzed against distilled water, and lyophilized. Samples were analyzed for the presence of gastric antigens by immunoelectrophoresis and for proteolytic activity at $\mathrm{pH} 1.9$ by characterization after electrophoresis in agar as described above. Five different mucosal extracts were separated in separate chromatographic runs, and comparable results were found for each.

Acidification of proenzymes before electrophoresis. Whole gastric extracts and products separated by chromatography were acidified by the addition of an equal volume of $0.06 \mathrm{M} \mathrm{HCl}$ (with a resultant $\mathrm{pH}$ of 2.0 ) and incubated at $37^{\circ} \mathrm{C}$ for 10 minutes. The acidified extract was then mixed with an equal volume of melted unbuffered 3\% agar and pipetted into the appropriate reservoir in the agar at $\mathrm{pH}$ 5.6. In experiments in which time of exposure to a given $\mathrm{pH}$ had to be limited, the $3 \%$ agar was made up in citrate buffer, $\mathrm{pH}$ 5.6.

\footnotetext{
${ }^{2}$ Nutritional Biochemicals Corp., Cleveland, Ohio.
} 
I.)termination of pH optimum of separated activated proenzymes. The method of Anson (10) was slightly modified. Separated and partially purified proteolytic constituents were dissolved in $0.9 \% \mathrm{NaCl}$. Five-tenths $\mathrm{ml}$ of $0.06 \mathrm{~N} \mathrm{HCl}$ was added to each of a series of tubes containing $0.5 \mathrm{ml}$ of the enzyme solution to be tested. After 10 minutes at $25^{\circ} \mathrm{C}, 2 \mathrm{ml}$ of $1 \%$ bovine hemoglobin ${ }^{3}$ dissolved in $0.2 \mathrm{M}$ glycine- $\mathrm{HCl}$ or $0.2 \mathrm{M}$ acetate buffer at the $\mathrm{pH}$ to be studied was added to the activated enzyme, and the mixture was incubated for 15 minutes at $25^{\circ} \mathrm{C}$. The reaction was stopped and protein precipitated by the addition of $3 \mathrm{ml}$ of $10 \%$ trichloroacetic acid. The contents of each tube were filtered, and the absorption at $280 \mathrm{~m} \mu$ was read against a blank composed of hemoglobin in the same buffer, to which the acidified enzyme had been added after the addition of trichloroacetic acid. A third tube containing substrate, buffer, and enzyme was not precipitated with trichloroacetic acid and was used to determine the $\mathrm{pH}$ of the substrate enzyme mixture.

Diffusion coefficient. The method of Allison and Humphrey was employed for the determination of the diffusion coefficient of P III (11).

\section{Results}

Chromatographic separation. Figure 1 shows the results of a chromatographic separation of gastric mucosal extract on DEAE-cellulose. The first proteolytic constituent eluted from the column was P IV. A nonproteolytic gastric antigen and

${ }^{3}$ Mann Research Laboratories, New York, N. Y. serum albumin were found in the same peak. No further purification of P IV was attempted. P III was eluted shortly after a peak rich in $260 \mathrm{~m} \mu$ absorbing material and remained present throughout the rest of the chromatograph in gradually decreasing quantities. The subsequent addition of $\mathrm{PO}_{4}$ buffer, $0.4 \mathrm{M}, \mathrm{pH} 5.65$, resulted in a protein peak rich in $\mathrm{P}$ II, but still containing $\mathrm{P}$ III. Finally, passage of $0.8 \mathrm{M} \mathrm{NaCl}$ in $0.4 \mathrm{M} \mathrm{PO}_{4}$ buffer at $\mathrm{pH} 5.4$ eluted a peak rich in $260 \mathrm{~m} \mu$ absorbing material. This peak contained P I, previously not eluted from the column, as well as traces of P II and P III.

Passage of the P II rich eluate through Sephadex G 25, G 50, G 100, and G 200 failed to separate the P III present from P II (12).

Change in electrophoretic mobility and immunochemical properties after acidification. Three representative mucosal extracts were acidified before electrophoresis to determine whether the mobility of the proteolytic constituents would be increased by this treatment. Electrophoresis was then carried out in agar buffered at $\mathrm{pH} 5.6$, since both pepsinogen and pepsin are stable at this $\mathrm{pH}$ (6). Results were the same for all stomachs studied. Representative findings are shown at the right of Figure 2. After acidification there was an in-

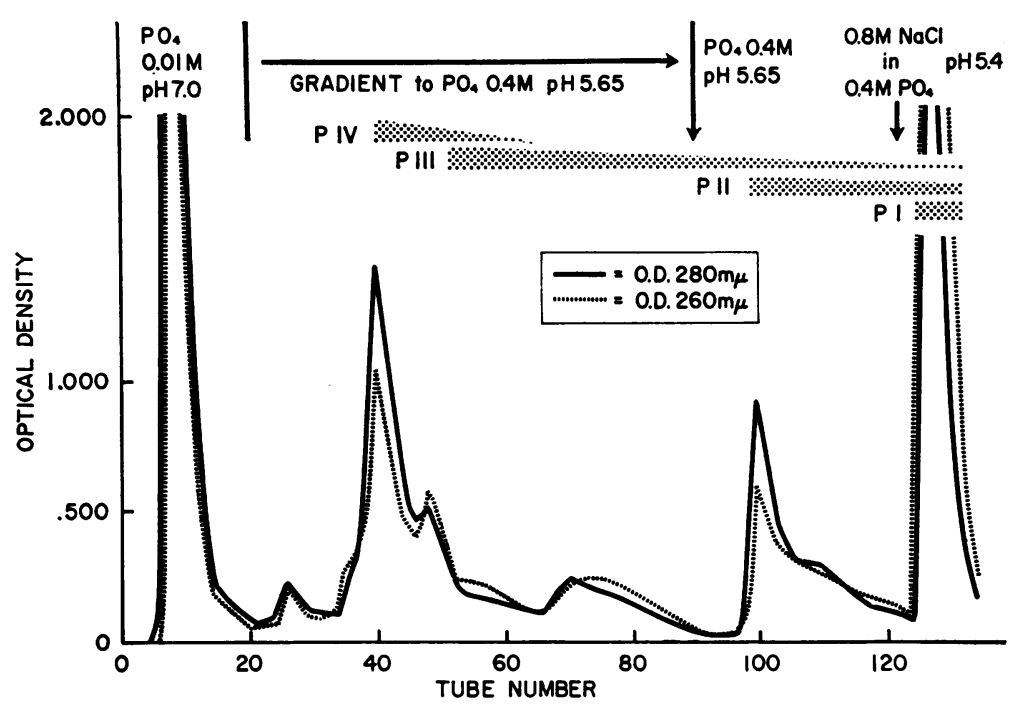

Fig. 1. DEAE-Cellulose chromatography of a REPRESENTAtive gasTRIC MUCOSAL EXTRACT. From patient with duodenal ulcer. Absorptions at $280 \mathrm{~m} \mu$ and $260 \mathrm{~m} \mu$ are indicated by a solid line and dashed line, respectively. The distribution of proteolytic constituents is indicated by horizontal bars above the curve. Diminished concentration is indicated by diminished thickness of the bar. 


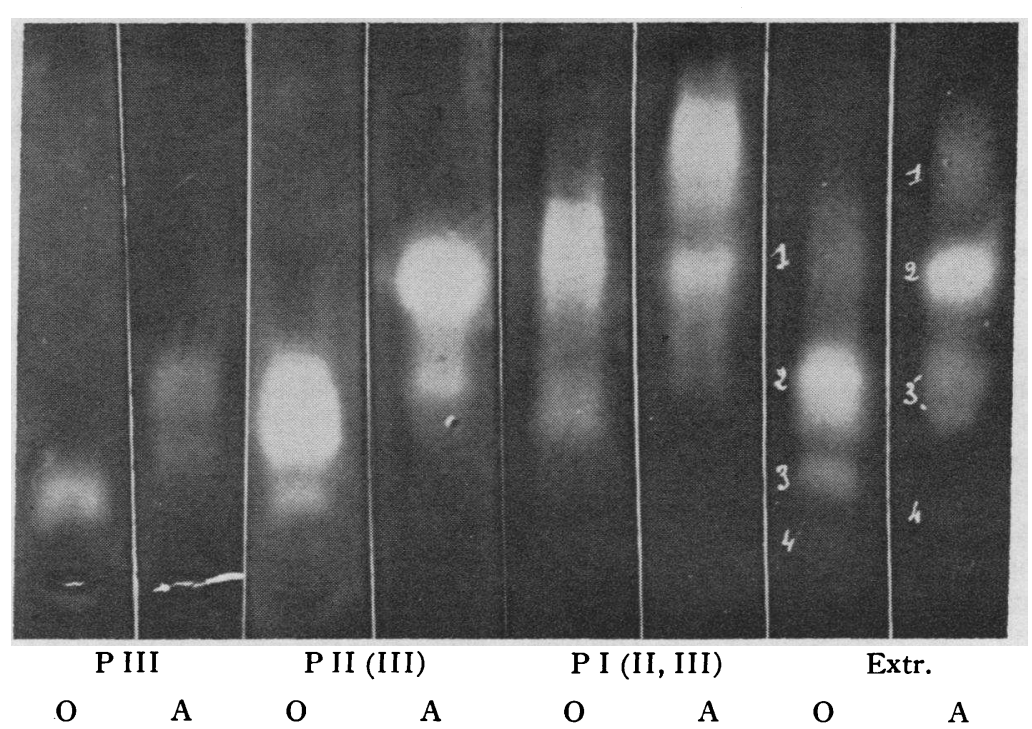

Fig. 2. Proteolytic activity After electrophoresis in Agar. Mucosal extracts from duodenal ulcer patients. The anode is at the top. The starting reservoir is visible at the bottom. The two strips at the right show whole mucosal extract before ( 0 ) and after (A) acidification. Four distinct proteolytic constituents are visible before acidification, the fourth being very weak. After acidification, five proteolytic spots of increased mobility are seen. Two of these are labeled 3. The pattern of proteolytic activity before and after acidification of the chromatographic fractions containing proteases (P) III, P II, and P I are also shown. P III gives rise to two proteolytic spots after acidification.

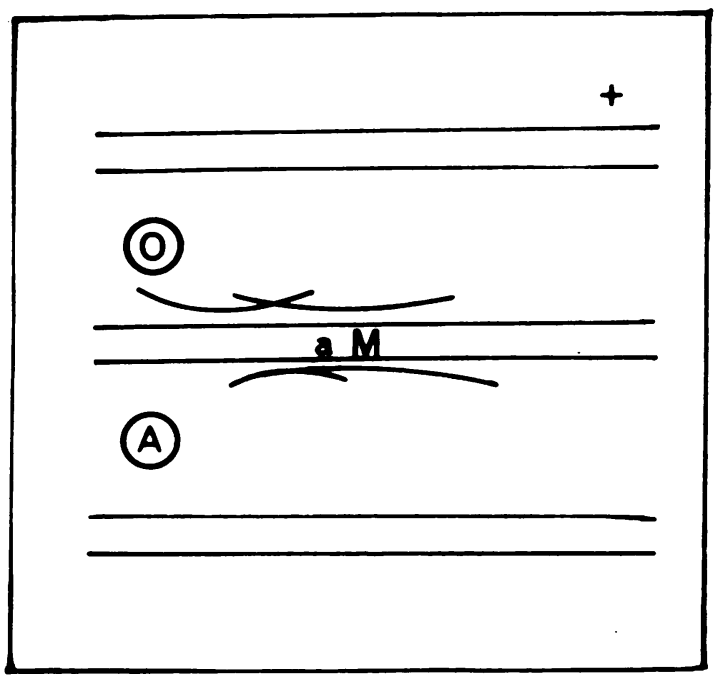

Fig. 3. IMMUNOELECTROPHORETIC PATTERN OF GASTRIC MUCOSAL EXTRACT BEFORE AND AFTER ACIDIFICATION. Duodenal ulcer patient. Migration in agar at $\mathrm{pH} 5.6$ for 1 hour. Well 0 , unacidified mucosal extract; well $\mathrm{A}$, acidified mucosal extract; aM, antimucosal antiserum containing antibodies to P II and P III. Both P II and $P$ III migrate more rapidly after acidification. crease in mobility of the ensemble of proteolytic constituents compared to that seen before acidification. Control studies showed that neither human serum albumin nor ovalbumin increased their electrophoretic mobility after acidification.

Upon IEA with antiserum containing antibodies to $\mathrm{P}$ II and P III, the mucosal extract showed two precipitin lines before acidification, and two somewhat weaker lines of more rapid mobility after acidification (Figure 3). When tested by the Ouchterlony technique at $\mathrm{pH} 5.6$, the precipitin lines formed against the acidified product were weaker than those against the original material. A very marked degree of cross-reactivity between the original and activated material was shown, with little if any spur formation (Figure 4). The same experiment performed in agar at $\mathrm{pH}$ 8.2 revealed no reaction with the acidified product. Absorption of this antiserum by acidified gastric extract removed activity against P II and P III (Figure 5a).

The effect of acidification of the proteolytic 
constituents separated or partially separated by chromatography was studied. A fraction containing P IV as the sole proteolytically active constituent demonstrated increased electrophoretic mobility of the proteolytic spot after acidification. Upon immunoelectrophoresis the mobility of the precipitin line representing this antigen increased by a like amount.

Figure 2 shows a similar experiment performed using other chromatographically separated fractions. When a fraction containing P III but devoid of other proteolytic activity and other gastric antigens was tested, two electrophoretically distinct

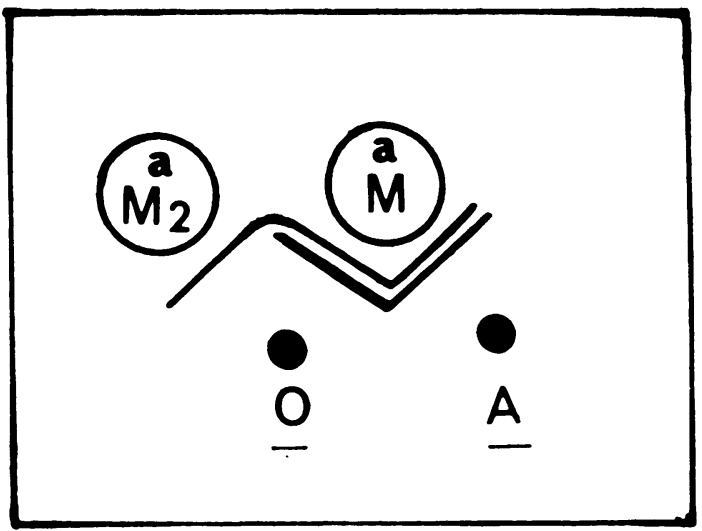

Fig. 4. Ouchterlony plate showing immunologic RELATIONSHIP BETWEEN ACIDIFIED AND UNACIDIFIED GASTRIC mUCosal eXtract. Duodenal ulcer patient. Agar at $\mathrm{pH}$ 5.6. Well 0 , unacidified extract; well $\mathrm{A}$, acidified extract; aM, antiserum (anti-P II and P III) ; $\mathrm{aM}_{2}$, antiserum (anti-P II). The reaction of aM with well $\mathrm{A}$ shows two lines weaker than those seen with well 0 . A sharp angle formed between the lines with little if any spur formation. At the concentration of extract employed, no other gastric antigens are detectable.

sites of proteolytic activity could be detected after acidification, both with a mobility more rapid than the original material. Upon immunoelectrophoresis with antiserum to P II and P III, the precipitin line formed by acidified P III was detected closer to the anode than the line formed against unacidified P III and showed a double curvature (Figure 6) consistent with the two proteolytic sites noted. This double curvature indicated that both of these enzymes are derived from a single precursor. Unacidified and acidified P III were placed in a single reservoir, and IEA was carried out. The precipitin line corresponding to the unacidified antigen fused with the more rapidly migrating line

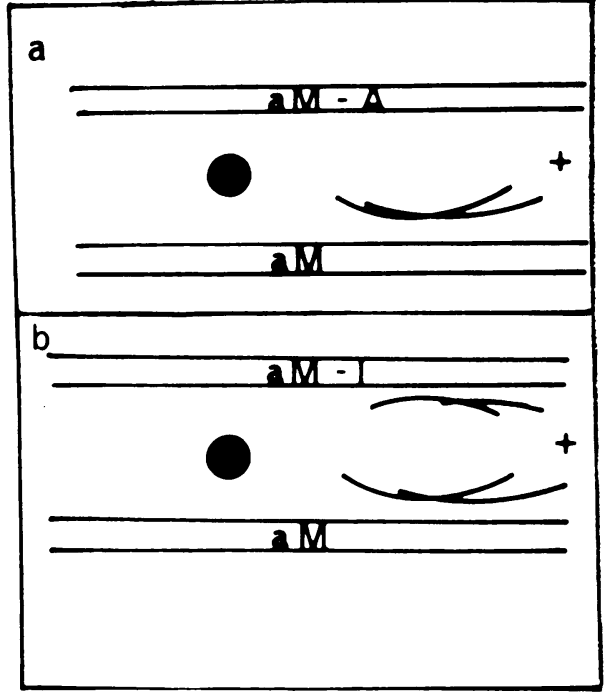

Fig. 5. Absorption of antiserum by activated And BY inACTIVATED EXTRACT. Duodenal ulcer patient. Immunoelectrophoretic analysis, migration in agar at $\mathrm{pH}$ 8.2 for $1 \frac{1}{2}$ hours. The well contains mucosal extract. a. Absorption of antiserum aM with acidified extract (aM-A) abolished detectable activity against the original extract. b. Absorption of antiserum with extract that has been inactivated by acidification and subsequent alkalinization (aM-I). The precipitin lines are closer to the aM-I antibody reservoir and are shorter, indicating partial absorption of antibody.

representing the activated enzyme to form a continuous line.

When a fraction containing primarily P II with a trace of P III was acidified, the mobility of the

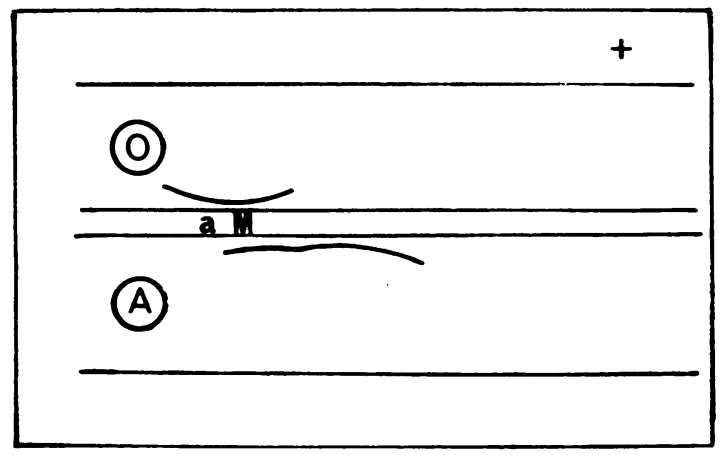

Fig. 6. IMMUNOELECTROPHORETIC PATTERN OF P III BEFORE AND AFTER ACIDIFICATION. Duodenal ulcer patient. Migration in agar at $\mathrm{pH}$ 5.6. Well $0, \mathrm{P}$ III unacidified; well A, P III acidified; aM, antiserum (anti-P II, P III). The precipitin line formed against acidified $P$ III presents a double curvature and is more anodally located than that formed with the unacidified P III. 


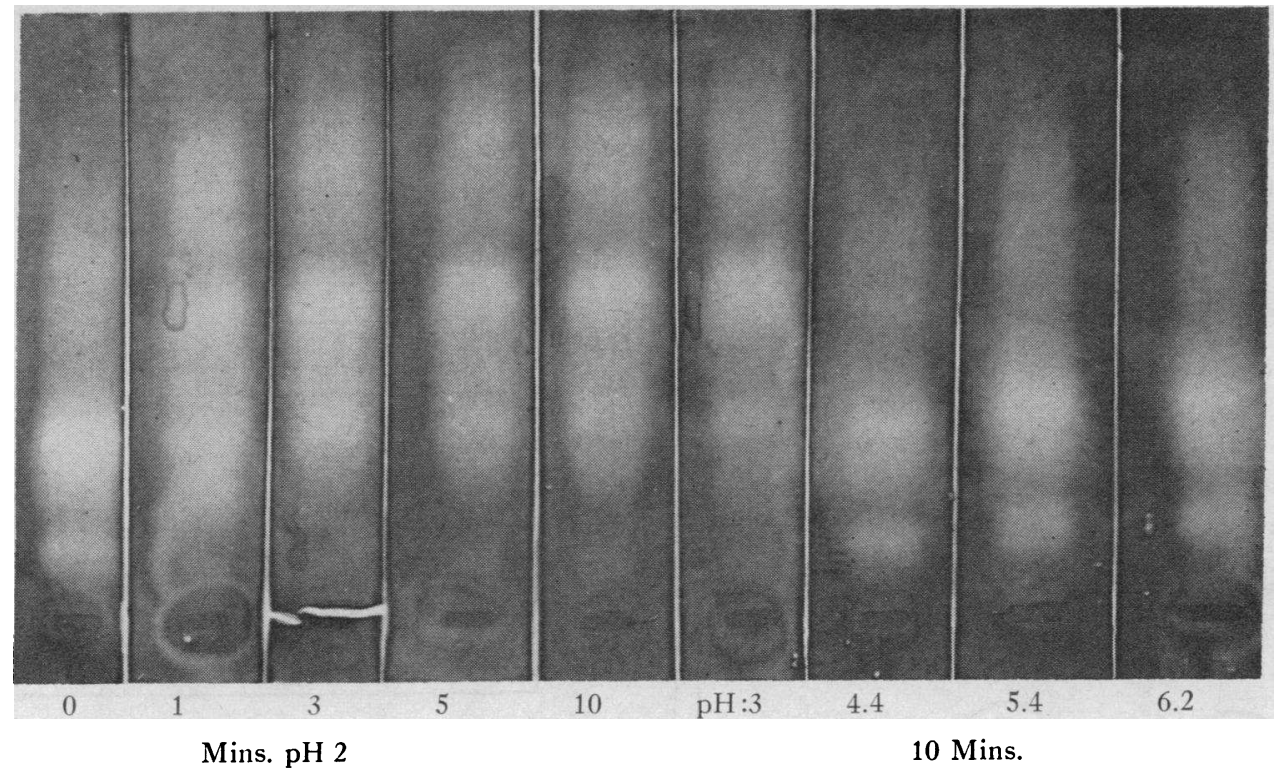

Fig. 7. PH ReQuirement and speed of activation. Duodenal ulcer patient. Left: Speed of activation at $\mathrm{pH}$ 2. Mucosal extract was adjusted to $\mathrm{pH} 2$ for $1,3,5$, and 10 minutes before being pipetted into the reservoirs. Electrophoresis in agar at $\mathrm{pH}$ 5.6. The change of mobility is almost complete by 1 minute and is complete by 3 minutes. Right : pH requirement. Extract incubated for 10 minutes at the $\mathrm{pH}$ 's indicated. Exposure to a $\mathrm{pH}$ of 4.4 or greater for periods of 10 minutes does not result in a significant change of mobility compared to the unacidified extract.

proteolytic P II spot was increased after acidification (Figure 2). Immunoelectrophoresis showed that the precipitin line of acidified P II was weaker and more anodally located. The chromatographic peak containing $\mathrm{P} I$, as well as small amounts of P II and P III, similarly showed that the mobility of $\mathrm{P}$ I increased after acidification (Figure 2).

All experiments described in this section were performed a total of three to five times on three different mucosal preparations from patients with duodenal ulcer. Findings were identical in each case.

$p H$ requirement and speed of activation. A single gastric extract was acidified at $\mathrm{pH} 2$ for periods of $1,3,5$, and 10 minutes. At the end of these intervals the extract was brought to $\mathrm{pH} 5.6$ by mixture with an equal volume of $3 \%$ agar in citrate buffer and placed in the reservoir. The results shown in the left half of Figure 7 indicate that by 1 minute activation was almost complete and that by 3 minutes it was completed.

The effect of incubating the same extract at $\mathrm{pH} 2.0,3.0,4.4,5.4$, and 6.2 for 10 minutes was studied. Activation was completed within this period of time at $\mathrm{pH} 2$ and 3 , but only minimally at $\mathrm{pH} 4.4$ and not at all at higher $\mathrm{pH}$ 's (Figure 7 , right).

Alkaline inactivation after acidification. Figure 8 shows that alkalinization of acidified gastric extract destroyed proteolytic activity. An equal quantity of gastric extract was placed in each of four tubes. The first and second tubes were diluted with normal saline, whereas the third and fourth were acidified for 10 minutes. The $\mathrm{pH}$ of the second and fourth tubes was then brought to $\mathrm{pH} 8.6$ by the dropwise addition of $0.5 \mathrm{M} \mathrm{NaOH}$ and $0.1 \mathrm{M} \mathrm{NaOH}$, whereas the first and third tubes were diluted with a comparable amount of normal saline. After 15 minutes, the contents of each tube were pipetted into reservoirs in the agar, and electrophoresis was performed. Alkalinization following acidification essentially eliminated the proteolytic activity of P I, P II, and P III. Identical findings were noted in each of three such experiments employing different mucosal extracts. Absorption of antiserum to P II and P III by this realkalinized extract in each case partially reduced 


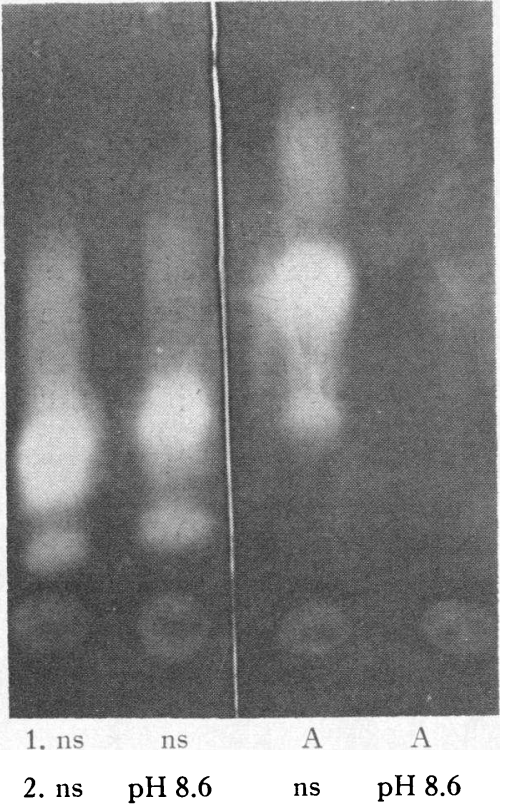

Fig. 8. Inactivation of PRoteolytic activity By ALKalinization of acidified MUCOSAL EXTRACt. Duodenal ulcer patient. $\mathrm{NS}=$ normal saline and $\mathrm{A}=$ acidified. See text for details.

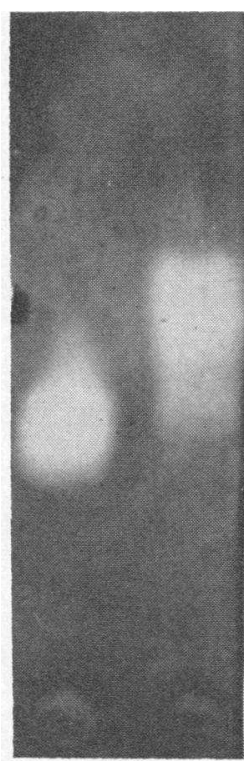

P'gen

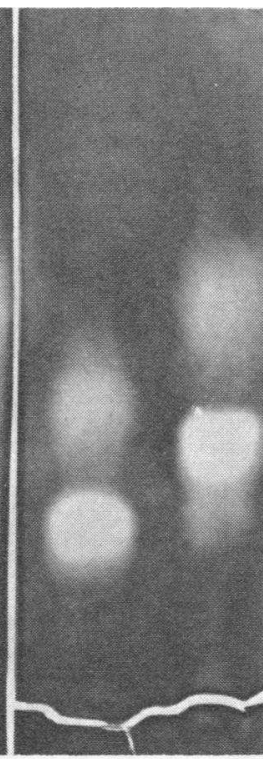

$\mathrm{O}$

A

the precipitin reaction against $\mathrm{P}$ II and $\mathrm{P}$ III (Figure 5b).

Since P IV was not well seen in this experiment, the procedure was repeated twice using a chromatographic fraction containing P IV as the only proteolytically active constituent. The activity of this acidified product was only minimally diminished by alkalinization.

Comparison with purified porcine pepsinogens. Samples of chromatographically purified porcine pepsinogen and pepsinogen $\mathrm{C}^{4}$ (13) were tested for proteolytic activity following electrophoresis in agar gel, before and after acidification (Figure 9). The results of each of three such experiments indicated that these zymogens had a mobility in the same general range as the human proenzymes and

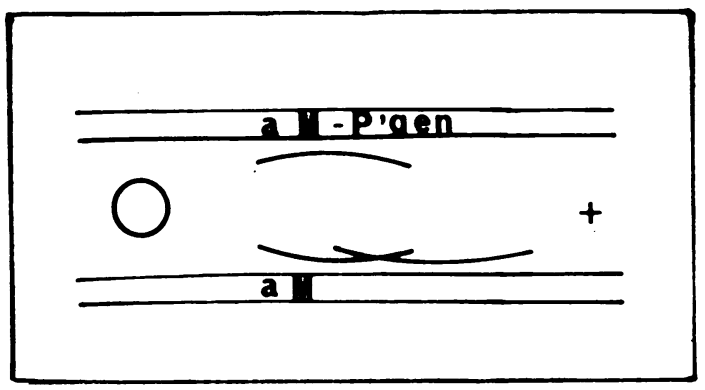

Fig. 10. AbSorption OF ANTISERUM With PORK PEPSINoGEN. The well contains mucosal extract. Antiserum containing antibodies against P II and P III (aM) was absorbed with porcine pepsinogen (aM-P'gen). Upon immunoelectrophoresis at $\mathrm{pH} 8.2$, the absorbed antiserum did not react with $\mathrm{P}$ II.

that their mobility increased in a similar manner after acidification.

A direct precipitin reaction was not demonstrated between porcine pepsinogen or pepsinogen $\mathrm{C}$ and antiserum containing antibodies to human $\mathrm{P}$ II and P III. Addition of pork pepsinogen to such antiserum, however, removed detectable reactivity against human P II (Figure 10) in each of two trials.

Diffusion coefficient. The diffusion coefficient of P III, determined 4 times on three different samples by the technique of Allison and Humphrey (11) was $7.7 \times 10^{-2} \mathrm{~cm}^{2}$ per second, only slightly different from that reported for porcine pepsinogen by Van Vunakis, Lehrer, Allison, and Levine

${ }^{4}$ Both kindly supplied by Dr. A. P. Ryle, the University of Edinburgh Medical School, Edinburgh. 

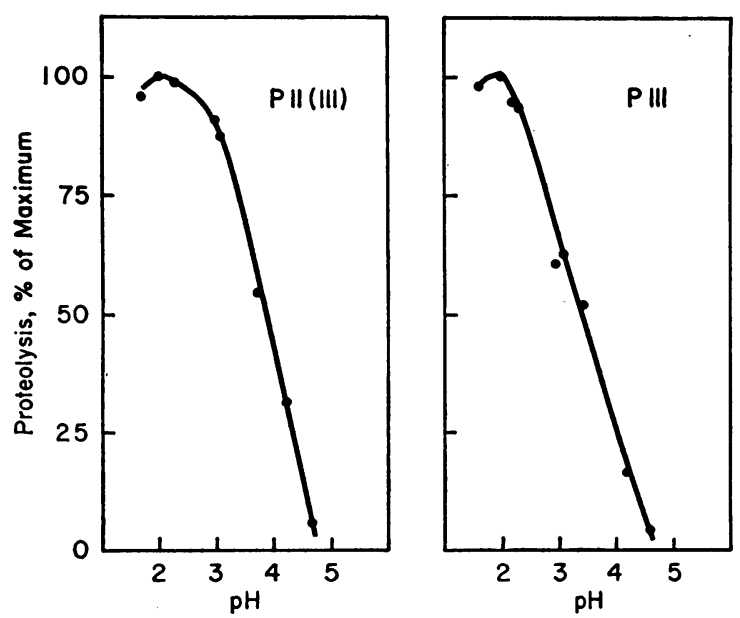

Fig. 11. pH Optima of activated P II and P III. Duodenal ulcer patient. See text for details. P III is at the right. A fraction containing primarily $\mathrm{P}$ II as well as a small amount of P III is at the left.

using the same technique (14). Attempts to determine the diffusion coefficient of P II were unsuccessful, due to the low level of antibody to this antigen and the consequent difficulty in arriving at a suitable ratio of antiserum to antigen.

$p H$ optima. The $\mathrm{pH}$ optima, after acidification, of P III and of the P II fraction containing a trace of P III were determined using bovine hemoglobin as substrate. Results, shown in Figure 11, are representative of identical findings in three determinations on two separate samples. In each case, optimal activity was found at $\mathrm{pH} 2.0$. However, whereas activated P III showed a sharp peak at $\mathrm{pH} 2.0$, optimal activity of partially purified and activated P II was found over a broader range extending toward the alkaline side. P I was not sufficiently purified for the $\mathrm{pH}$ optimum to be determined. P IV was too weakly proteolytic for the $\mathrm{pH}$ optimum to be accurately determined.

\section{Discussion}

Previous studies performed in this laboratory (1) have shown four electrophoretically distinct proteolytic constituents active at $\mathrm{pH} 2$ in extracts of each of 45 noncancerous stomachs studied. Extraction was carried out at $\mathrm{pH} 8.0$ and electrophoresis at $\mathrm{pH} 8.2$, ruling out the possibility that these four components represented modifications of a single protein due to acid activation.

In the present work evidence is presented that human gastric mucosa contains four distinct proenzymes giving rise to five enzymes with pepsinlike activity. These four constituents differed from one another physicochemically, demonstrating differing electrophoretic mobilities and elution patterns upon chromatography on DEAE-cellulose. In addition, they differed from one another immunochemically in that three of them demonstrated unrelated precipitin arcs on immunoelectrophoresis, whereas the fourth constituent (P I) did not appear to be antigenic.

The evidence that these constituents represent precursors of pepsin-like enzymes may be summarized as follows: 1) Each constituent demonstrated proteolytic activity at or near $\mathrm{pH} 2.0$, either when tested in tubes by the Anson hemoglobin assay method or in agar after electrophoresis. 2) The components were extracted from gastric mucosa under alkaline conditions. Pepsinogen is stable under these conditions, whereas all but one of the known pepsins are inactivated (see below) $(7,15)$. 3) After acidification, the electrophoretic mobility of each proteolytically active constituent increased. This is consistent with the loss of basic peptides known to occur upon the conversion of pepsinogen to pepsin. This change in mobility occurred under the same conditions of $\mathrm{pH}$ and as rapidly as does the activation of pepsinogen to pepsin (4). 4) Once activated, return to an alkaline $\mathrm{pH}$ resulted in complete or almost complete loss of proteolytic activity of all constituents except P IV. 5) The range of electrophoretic mobility and the change in mobility following activation are similar to those of porcine pepsinogen and pepsinogen $\mathrm{C}$.

The studies described in the present report, demonstrating that the four proteolytic constituents of gastric mucosal extracts are proenzymes, were performed with mucosal extracts of stomachs from patients with duodenal ulcer. These studies strongly suggest that the four proteolytic constituents of identical mobility and immunochemical characteristics also found in normals and in gastric ulcer patients similarly represent four distinct pepsinogens.

Preliminary studies of human gastric juice performed with Dr. H. Hirsch-Marie have revealed proteolytic activity in at least three electrophoretically separate sites comparable in mobility to those reported here for the three more rapid pro- 
enzymes after activation. In addition, antiserum to P II and P III reacted with gastric juice on immunoelectrophoresis to give two lines with a mobility and appearance identical to those of activated P II and P III.

In the present work it has been shown that antisera to the three antigenic human proenzymes, $\mathrm{P}$ II, III, and IV, are reactive with the activated more rapidly migrating enzymes. After activation each antigen was shown by IEA to migrate more rapidly. Absorption of antiserum to P II and P III by activated mucosal extracts abolished activity against these constituents, whereas absorption by activated and subsequently alkalinized extracts only partially abolished reactivity to these antigens.

Studies employing the Ouchterlony technique revealed a high degree of cross-reactivity between P II and activated P II and between P III and activated P III. Fusion of the lines representing unactivated and activated P II upon immunoelectrophoresis also indicated a close immunologic relationship between these components. No reaction betwen antiserum to P II and P III and acidified extract could be detected at $\mathrm{pH} 8.2$, consistent with denaturation of these acidified constituents at this $\mathrm{pH}$. In studies of the immunochemical behavior of the pepsinogen-pepsin system, Van Vunakis and his colleagues (14), and Schlamowitz, Varandani, and Wissler (6) found porcine pepsinogen to be weakly antigenic. Cross-reactivity between pepsinogen and pepsin was demonstrated by both of these groups at $\mathrm{pH} 5.5$ with greatly diminished cross-reactivity at $\mathrm{pH} 8$. Thus, the immunochemical findings described in the present report are in agreement with the known immunochemical behavior of the pork pepsinogen system and lend additional support to the thesis that each of these constituents is indeed a distinct molecular species of human pepsinogen.

Multiple porcine pepsins were demonstrated by Ryle and Porter (7) who separated para-pepsin I and para-pepsin II (since designated pepsin B and pepsin C) from pepsinogen. Pepsin B produces almost no degradation of protein substrates, although it hydrolyzes the synthetic substrate acetylDL-phenylalanyl L-diiodotyrosine (APD). Its activity is unaffected by alkalinization. Pepsin C digests bovine hemoglobin and bovine plasma albumin, but not APD, and is inactivated by alka- linization. Pepsin itself digests both $\Lambda P D$ and the protein substrates and is known to be quite unstable in alkaline solution.

In subsequent work Ryle (13) reported the isolation of pepsinogen $C$, the zymogen of pepsin $C$, from extracts of porcine gastric mucosa and demonstrated that activation of the proenzyme was extremely rapid at $\mathrm{pH} 2.0$ and much slower at $\mathrm{pH}$ values greater than 4.0. Recently, Lee and Ryle (16) have succeeded in isolating a fourth zymogen, pepsinogen $\mathrm{D}$, from porcine gastric mucosa.

Tang, Wolf, Caputto, and Trucco (17) demonstrated a proteolytic enzyme, gastricsin, in human gastric juice with optimal activity at $\mathrm{pH} 3.0$ to 3.2, whereas the $\mathrm{pH}$ optimum of human pepsin was 2.0. Tang and Tang (15) subsequently reported the purification from human gastric mucosa of zymogen IA which, upon acidification, was converted to two proteolytically active constituents demonstrating the properties of pepsin and gastricsin, respectively. Both of these latter enzymes were inactivated by alkalinization.

It is difficult to relate human pepsinogen I described in this report to known components of the porcine or human pepsinogen systems. It could not be shown to be antigenic under the experimental conditions employed. In view of the $\mathrm{pH}$ at which extraction was carried out it seems unlikely that P I represents a proteolytically active product of autodigestion of the other proenzymes or enzymes. The possibility that this component was split from another pepsinogen during lyophilization cannot be excluded.

Human pepsinogen II, on the other hand, is clearly immunologically related to Ryle's pork pepsinogen as shown by absorption studies. The $\mathrm{pH}$ maximum at $\mathrm{pH} 2.0$ of activated P II was not followed by a clear second maximum at $\mathrm{pH} 3$, even after activation for 1 hour. However, the broad $\mathrm{pH}$ range over which $\mathrm{P}$ II is active may suggest that it corresponds to human zymogen IA (15), which has been shown to give rise to pepsin and gastricsin with $\mathrm{pH}$ maxima at 2 and 3 , respectively. The possibility that this proenzyme actually gives rise to two electrophoretically different enzymes after activation cannot be ruled out, since the sample studied contained a trace of P III, which might mask a second proteolytic spot.

Human pepsinogen III apparently gives rise to two enzymes upon activation, as demonstrated by 
electrophoresis and confirmed by immunoelectrophoresis. However, the sharp $\mathrm{pH}$ optimum at $\mathrm{pH} 2.0$ shown by $\mathrm{P}$ III after activation makes it unlikely that gastricsin could be derived from this proenzyme.

Because of its mucosal origin and accelerated mobility following acidification, P IV probably represents a proenzyme as well. However, the possibility that this constituent is the enzyme itself cannot be ruled out, since it is not inactivated by alkalinization and would not be denatured by the extraction procedure. P IV does not appear to be immunologically related to the other human pepsinogens, and it is thus unlikely that it represents an enzymatically active degradation product of the others or that it is a denatured pepsin. The $\mathrm{pH}$ optimum shown by $\mathrm{P}$ IV in agar establishes it as belonging to the pepsin group. P IV is stable upon alkalinization, is the most basic of the human pepsinogens, and demonstrates only weak activity against protein substrates, all properties analogous to those of swine pepsinogen $\mathrm{B}$. These findings suggest that P IV may be related to this porcine zymogen.

The nomenclature we have employed for the human pepsinogens is based on the electrophoretic mobility of these components. It may lead to problems vis-à-vis the well studied pork pepsinogen-pepsin system, where nomenclature has been based on other criteria. Until more complete characterization of the human pepsinogens can be carried out, it seems wise to retain the nomenclature that we have employed.

The cellular origin of these pepsinogens is unknown. Germane to this problem are experiments performed in this laboratory (18) which demonstrated that the pyloric portion of the stomach contains P III and P IV, whereas all four pepsinogens are present in the body and fundus. The results are consistent with the findings reviewed by Taylor of peptic activity in mammalian pyloric mucosa (19).

\section{Summary}

Four electrophoretically distinct constituents present in alkaline extracts of human gastric mucosa display peptic activity. Three of these (P I, P II, and P III) have been shown to behave like pepsinogen by an augmentation of electrophoretic mobility following acidification, by the speed and
$\mathrm{pH}$ requirements of the augmentation, by loss of proteolytic activity following realkalinization, and, in the case of two of these constituents (P II and P III), by the demonstration of an immunologic relationship between the acidified and the original antigen. The fourth component (P IV) also migrated more rapidly after acidification, but was not inactivated by subsequent alkalinization. Antiserum to $\mathrm{P}$ IV reacted with acidified P IV upon immunoelectrophoretic analysis to give a precipitin reaction more anodally located than unacidified P IV.

These human pepsinogens could be separated from one another partially or completely by anion exchange chromatography. P II was shown to be immunologically related to purified pork pepsinogen. P III showed a diffusion coefficient approximately the same as that of pork pepsinogen and gave rise to two electrophoretically distinct proteolytic components upon activation. Activated $\mathrm{P}$ IV displayed several characteristics in common with pork pepsin B. ${ }^{5}$

\section{Acknowledgments}

Dr. Kushner particularly expresses his gratitude for the kindness shown to him by Dr. Pierre Grabar.

We gratefully acknowledge the technical assistance of Miss Karin Goldman.

\section{References}

1. Rapp, W., S. B. Aronson, P. Burtin, and P. Grabar. Constituents and antigens of normal human gastric mucosa as characterized by electrophoresis and immunoelectrophoresis in agar gel. J. Immunol. 1964, 92, 579.

2. Uriel, J. The direct detection of proteolytic enzymes after electrophoresis in agar gel. Nature (Lond.) 1960, 188, 853.

3. Aronson, S. B., W. Rapp, I. Kushner, and P. Burtin. Evaluation of normal gastric mucosal antigens and enzymes in cancerous human gastric mucosa by agar and immunoelectrophoresis. Proc. Soc. exp. Biol. (N. Y.), in press.

4. Hirschowitz, B. F. Pepsinogen : its origins, secretion, and excretion. Physiol. Rev. 1957, 37, 475.

5 During revision of this manuscript, Seijffers, Segal, and Miller reported the separation of three pepsinogens (I, II, and III) and four pepsins from human gastric mucosa by chromatographic means $(20,21)$. These pepsinogens apparently correspond respectively to pepsinogens III, II, and I described in the present report. 
5. Herriott, R. M. Pepsinogen and pepsin. J. gen. Physiol. 1962, 45 (suppl.), 57.

6. Schlamowitz, M., P. T. Varandani, and F. C. Wissler. Pepsinogen and pepsin: conformational relations, studied by iodination, immunochemical precipitation, and the influence of pepsin inhibitor. Biochemistry 1963, 2, 238.

7. Ryle, A. P., and R. R. Porter. Parapepsins: two proteolytic enzymes associated with porcine pepsin. Biochem. J. 1959, 73, 75.

8. Grabar, P., and P. Burtin. Analyse Immunoélectrophorétique. Paris, Masson, 1960.

9. Fahey, J. L., P. F. McCoy, and M. Goulian. Chromatography of serum proteins in normal and pathologic sera: the distribution of protein-bound carbohydrate and cholesterol, siderophilin, thyroxinbinding protein, $\mathrm{B}_{12}$ binding protein, alkaline and acid phosphatases, radioiodinated albumin and myeloma proteins. J. clin. Invest. 1958, 37, 272.

10. Anson, M. L. Estimation of pepsin, trypsin, papain and cathepsin with hemoglobin. J. gen. Physiol. 1938, 22, 79.

11. Allison, A. C., and J. H. Humphrey. Estimation of the size of antigens by gel diffusion methods. Nature (Lond.) 1959, 183, 1590.

12. Porath, J. Cross linked dextrans as molecular sieves in Advances in Protein Chemistry. New York, Academic Press, 1962, vol. 17, p. 209.
13. Ryle, A. P. Parapepsinogen II: the zymogen of parapepsin II. Biochem. J. 1960, 75, 145.

14. Van Vunakis, H., H. I. Lehrer, W. S. Allison, and L. Levine. Immunochemical studies on the components of the pepsinogen system. J. gen. Physiol. 1963, 46, 589.

15. Tang, J., and K. I. Tang. Purification and properties of a zymogen from human gastric mucosa. J. biol. Chem. 1963, 238, 606.

16. Lee, D., and A. P. Ryle. Pepsinogen D, a zymogen from pig gastric mucosa. Biochem. J. 1963, 87, 44P.

17. Tang, J., S. Wolf, R. Caputto, and R. E. Trucco. Isolation and crystallization of gastricsin from human gastric juice. J. biol. Chem. 1959, 234, 1174.

18. Kushner, I., W. Rapp, and P. Burtin. Unpublished data.

19. Taylor, W. H. Proteinases of the stomach in health and disease. Physiol. Rev. 1962, 42, 519.

20. Seijffers, M. J., H. L. Segal, and L. L. Miller. Separation of pepsin I, pepsin II A, pepsin II B and pepsin III from human gastric mucosa. Amer. J. Physiol. 1963, 205, 1099.

21. Seijffers, M. J., H. L. Segal, and L. L. Miller. Separation of pepsinogen I, pepsinogen II, and pepsinogen III from human gastric mucosa. Amer. J. Physiol. 1963, 205, 1106. 